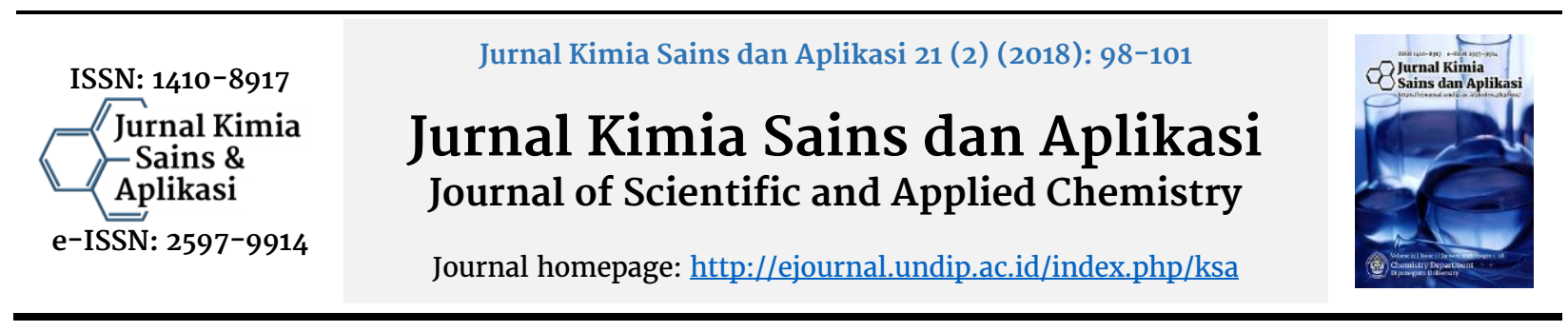

\title{
Natural Zeolite Modification using Dithizone and Its Application as Adsorbent of $\mathrm{Cu}(\mathrm{II})$
}

\author{
Agnidian Setyorini ${ }^{a}$, Suhartana ${ }^{a^{*}}$, Pardoyo $^{\text {a }}$ \\ a Inorganic Chemistry Laboratory, Chemistry Department, Faculty of Sciences and Mathematics, Diponegoro University, Jalan Prof. \\ Soedarto, Tembalang, Semarang \\ * Corresponding author: suhartana@live.undip.ac.id
}

\section{Article Info}

Keywords:

Zeolite, Dithizone, Adsorption

\section{Abstract}

Activation of zeolites with dithizone by reflux method was carried out at $50^{\circ} \mathrm{C}$ for 6 hours and the results were analyzed using FTIR and GSA. Furthermore, the modified zeolite dithizone was used to adsorb $\mathrm{Cu}^{2+}$ metal ions on variations of adsorption time of 5,10 , 15,30 and $60 \mathrm{~min}$, variation of adsorption $\mathrm{pH} \mathrm{2,3,4,5}$ and 6 as well as variations in concentrations of 250, 500,1000, 1500 and $2000 \mathrm{ppm}$. The results showed that there was a vibrational shift and a new peak emerged on the FTIR zeolite activation spectrum and modified zeolite indicating that the dithizone was present in the zeolite. GSA analysis results show that the surface area of activated zeolite is greater than natural zeolite ie 4,205 $\mathrm{m}^{2} / \mathrm{g}$ and 5,459 $\mathrm{m}^{2} / \mathrm{g}$ respectively, whereas dithizone-zeolite had a much smaller surface area of $0.925 \mathrm{~m}^{2} / \mathrm{g}$. The selectivity of adsorption of activated zeolite to $\mathrm{Cu}$ (II) was greater than of dithizone-zeolite. The optimum adsorption contact time was $10 \mathrm{~min}$ for dithizone-zeolite and $30 \mathrm{~min}$ for activated zeolite. The optimum adsorption $\mathrm{pH}$ was at $\mathrm{pH} 5$ for both adsorbents, as well as the optimum adsorption concentration at $250 \mathrm{ppm}$ for both adsorbents.

\section{Abstrak}

Aktivasi zeolit dengan ditizon dengan metode refluks telah dilakukan pada suhu $50^{\circ} \mathrm{C}$ selama 6 jam dan hasilnya dianalisis menggunakan FTIR dan GSA. Selanjutnya, zeolit termodifikasi ditizon digunakan untuk mengadsorpsi ion logam Cu2+ pada variasi waktu kontak adsorpsi 5, 10, 15, 30 dan 60 menit, variasi pH adsorpsi 2, 3, 4, 5 dan 6 serta variasi konsentrasi 250, 500, 1000, 1500 dan 2000 ppm. Hasil penelitian menunjukkan bahwa terjadi pergeseran vibrasi dan muncul peak baru pada spektra FTIR zeolit aktivasi dan zeolit termodifikasi yang menunjukkan bahwa ditizon telah ada dalam zeolit. Hasil analisis GSA menunjukkan bahwa luas permukaan zeolit teraktivasi lebih besar daripada zeolit alam yaitu masing-masing 4,205 $\mathrm{m}^{2} / \mathrm{g}$ dan 5,459 $\mathrm{m}^{2} / \mathrm{g}$, sedangkan zeolit ditizon memiliki luas permukaan yang jauh lebih kecil yaitu $0,925 \mathrm{~m}^{2} / \mathrm{g}$. Selektivitas adsorpsi zeolit aktivasi terhadap ion logam $\mathrm{Cu}$ lebih besar daripada zeolit ditizon. Diperoleh waktu kontak adsorpsi optimum 10 menit untuk zeolit ditizon dan 30 menit untuk zeolit aktivasi. pH adsorpsi optimum berada pada $\mathrm{pH} 5$ untuk kedua adsorben, begitu pula konsentrasi adsorpsi optimum pada 250 ppm untuk kedua adsorben.

\section{Pendahuluan}

Tembaga termasuk ke dalam logam berat esensial, artinya meskipun bearacun dalam jumlah tertentu sangat dibutuhkan oleh organisme. Toksisitas dari logam tembaga baru akan bekerja dan memperlihatkan pengaruhnya bila logam ini telah masuk ke dalam tubuh organisme dalam jumlah besar atau melebihi nilai ambang batasnya [1].

Beberapa metode yang dapat dilakukan untuk mengolah ion logam berat antara lain adalah netralisasi, 
presipitasi, pertukaran ion, biosorpsi, dan adsorpsi. Adsorpsi dapat dilakukan terhadap logam berat dengan menggunakan berbagai macam adsorben, di antaranya adalah zeolit, alofan, kitin-khitosan, biosorben dari spesies alga, fly ash, karbon aktif dan selulosa [2].

Bagian permukaan zeolit sangat luas, sehingga sangat baik bila dimanfaatkan sebagai adsorben [3]. Zeolit meskipun ketersediaannya sangat melimpah, kristalinitas zeolit alam tidak terlalu tinggi, ukuran pori tidak seragam, aktivitas katalitik rendah, dan mengandung banyak pengotor. Oleh karena itu, zeolit perlu diaktivasi, dan dimodifikasi sebelum digunakan sebagai penjerap logam berat [4].

Ditizon merupakan ligan yang sensitif dan spesifik karena mengandung banyak atom donor $\mathrm{N}$, gugus - $\mathrm{NH}$ serta -SH sebagai donor pasangan elektron membentuk khelat dengan adsorben dalam mengadsorpsi ion logam transisi termasuk $\mathrm{Pb}, \mathrm{Cd}$ dan $\mathrm{Hg}$ [5]. Penelitian ini dilakukan untuk memodifikasi zeolit alam menggunakan ditizon dengan tujuan menigkatkan kemampuan adsorpsi zeolit terhadap ion logam $\mathrm{Cu}$ (II).

\section{Metode Penelitian}

\section{Alat dan Bahan}

Bahan yang digunakan dalam penelitian ini adalah ditizon, zeolit alam Bayat Klaten, tembaga sulfat pentahidrat, etanol $96 \%$, dietil eter, asam klorida $3 \mathrm{M}$, asam klorida $0,1 \mathrm{M}$, natrium hidroksida $0,1 \mathrm{M}$, aquades. Peralatan yang digunakan dalam penelitian ini adalah yang digunakan dalam penelitian ini adalah gelas standar penelitian, vial, pipet, stirer, vakum, oven, satu set alat refluks, FTIR shimadzu, Quantachrome AsiQwin Automated Gas Sorption, AAS.

\section{Preparasi dan Aktivasi Zeolit Alam}

Zeolit alam Bayat Klaten dicuci dengan aquades , dikeringkan, dihaluskan dan diayak 170 mesh. Disaring dengan pompa vakum dan dikeringkan. Zeolit alam $50 \mathrm{~g}$ direndam ke dalam $100 \mathrm{~mL}$ larutan $\mathrm{HCl}$ 3N selama 24 jam. dikeringkan pada suhu $120^{\circ} \mathrm{C}$ selama 3 jam. Zeolit alam dikarakterisasi dengan Spektroskopi Fourir Transform Infrared (FT-IR) serapan atom untuk mengetahui gugus fungsi sebelum dilakukan modifikasi dengan ditizon.

\section{Modifikasi Zeolit}

Difeniltiokarbazon (ditizon) sebanyak 2,56 gram ( 10,0 mmol) dimasukkan ke dalam $500 \mathrm{~mL}$ labu bulat dan dilarutkan sempurna dalam $400 \mathrm{~mL}$ etanol $96 \%$ dengan pemanasan pada $50^{\circ} \mathrm{C}$. Larutan kemudian ditambah dengan 10 gram zeolit alam dan direaksikan selama 6 jam pada suhu tersebut. Fase zeolit yang telah dimodifikasi disaring dan dicuci menggunakan $50 \mathrm{~mL}$ etanol sebanyak tiga kali ulangan kemudian dicuci dengan $50 \mathrm{~mL}$ dietil eter. Hasil yang dihasilkan kemudian dikeringkan-udarakan semalam [6]. Zeolit ditizon (ZD) yang diperoleh kemudian dikarakterisasi dengan menggunakan Fourir Transform Infrared (FT-IR) spektroskopi serapan atom untuk mengetahui gugus fungsi setelah dilakukan modifikasi dengan ditizon.

\section{Uji Adsorpsi}

Pada uji ini dilakukan 3 variasi yaitu variasi waktu kontak, pH dan konsentrasi. Variasi waktu kontak dilakukan dengan mencampurkan $25 \mathrm{ml}$ larutan ion $\mathrm{Cu}$ (II) 500 ppm dengan 0,2 gram zeolit ditizon divariasikan dengan waktu kontak 5, 10, 15, 30 dan 60 menit. Konsentrasi filtrat diukur menggunakan spektrometer serapan atom [7]. Perlakuan di atas diulang dengan zeolit alam.

Variasi $\mathrm{pH}$ 2, 3, 4, 5 dan 6 dilakukan dengan menambahkan $\mathrm{NaOH} 0.1 \mathrm{M}$ atau $\mathrm{HCl} 0.1 \mathrm{M}$ tetes demi tetes. Setelah pH tercapai, sebanyak $0.2 \mathrm{~g}$ zeolit ditizon dimasukkan ke dalam erlenmeyer dan ditutup. Larutan dikocok menggunakan magnetik stirer selama waktu kontak optimum, lalu disaring. Filtrat dianalisis konsentrasinya menggunakan spektrometer serapan atom [7]. Perlakuan di atas diulangi dengan menggunakan zeolit alam.

Sebanyak $25 \mathrm{~mL}$ larutan ion $\mathrm{Cu}$ (II) divariasikan konsentrasinya menjadi 250, 500, 1000, 1500 dan 2000 ppm, kemudian dimasukkan ke dalam erlenmeyer 100 mL. Setelah itu, sebanyak $0.2 \mathrm{~g}$ zeolit termodifikasi ditizon dimasukkan ke dalam rlenmeyer dan ditutup. Larutan dikocok menggunakan magnetik stirer dengan waktu kontak dan $\mathrm{pH}$ optimum. Konsentrasi filtrat diukur menggunakan spektrometer serapan atom [7]. Perlakuan di atas diulang dengan zeolit alam.

\section{Hasil dan Pembahasan}

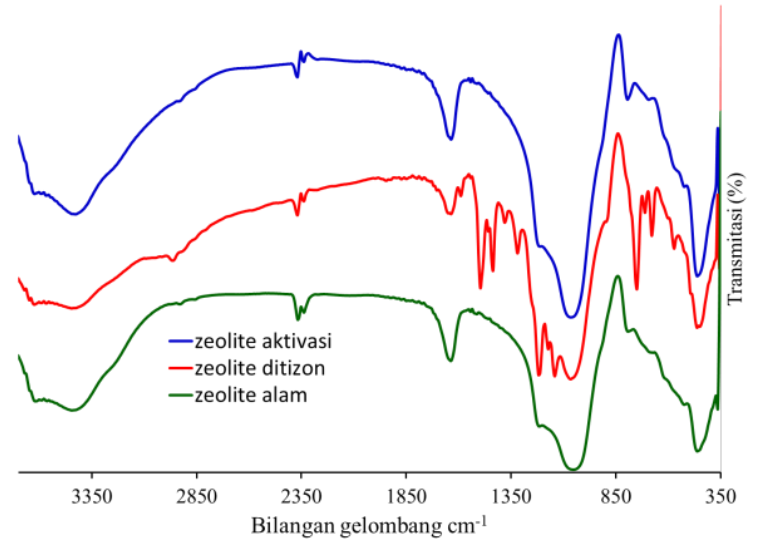

Gambar 1. Spektra FTIR Zeolit Alam, Zeolit Aktivasi dan Zeolit Ditizon

Secara spektroskopis, zeolit dapat diamati pada rentang bilangan gelombang $300-1300 \mathrm{~cm}^{-1}$. Bilangan gelombang tersebut merupakan daerah utama serapan ikatan tetrahedral dari komponen utama penyusun zeolit, $\mathrm{SiO}_{4}{ }^{4-}$ dan $\mathrm{AlO}_{4}{ }^{5-}$. Rentangan simetri O-Al-O atau $\mathrm{O}-\mathrm{Si}-\mathrm{O}$ pada internal tetrahedral akan muncul pada daerah $650-720 \mathrm{~cm}^{-1}$ sedang untuk pertautan eksternal akan muncul pada $750-820 \mathrm{~cm}^{-1}$. Tekukan Si-O atau Al$\mathrm{O}$ akan muncul pada daerah $420-500 \mathrm{~cm}^{-1}$, sedangkan serapan pada daerah 950-1250 $\mathrm{cm}^{-1}$ menunjukkan rentangan asimetri (Wietkamp dan Puppe 1999). Rentangan asimetri zeolit alam sebelum dan sesudah aktivasi pada penelitian ini ditunjukkan pada pita $1049,28 \mathrm{~cm}^{-1}$ dan $1064,71 \mathrm{~cm}^{-1}$. Pada gambar 1 terlihat 
bahwa ada beberapa pergeseran spektra dari zeolit aktif menjadi zeolit ditizon yaitu pada bilangan gelombang $462,92 \mathrm{~cm}^{-1}$ menjadi $447,49 \mathrm{~cm}^{-1}$ yang menunjukkan vibrasi tekuk Si-O dan Al-O, 794,67 $\mathrm{cm}^{-1}$ menjadi 748,38 $\mathrm{cm}^{-1}$ yang merupakan vibrasi tekuk $\mathrm{Si}-\mathrm{O}$, serta pada $3425,58 \mathrm{~cm}^{-1}$ menjadi 3433,29 $\mathrm{cm}^{-1}$ yang merupakan vibrasi ulur $\mathrm{O}-\mathrm{H}$. Selain itu ada beberapa serapan baru yang muncul dalam spektra zeolit ditizon yaitu pada $1141,86 \mathrm{~cm}^{-1}$ yang menandai vibrasi ulur $-\mathrm{C}=\mathrm{S}, 1496,76$ $\mathrm{cm}^{-1}$ menandai vibrasi tekuk $-\mathrm{NH}, 1435,04 \mathrm{~cm}^{-1}$ menandai vibrasi ulur $-\mathrm{N}=\mathrm{N}-, 2445,74 \mathrm{~cm}^{-1}$ menandai vibrasi $-\mathrm{SH}, 2276 \mathrm{~cm}^{-1}$ menandai vibrasi $\mathrm{C}=\mathrm{N}, 2962,66$ $\mathrm{cm}^{-1}$ menandai vibrasi $-\mathrm{C}-\mathrm{N}$ - dari ditizon, selain itu pada $3093,82 \mathrm{~cm}^{-1}$ menandai ikatan $\mathrm{C}-\mathrm{H}$ aromatik yang makin memperkuat bahwa zeolit aktif telah termodifikasi ditizon.

Pengaruh waktu kontak pada adsorpsi ion logam

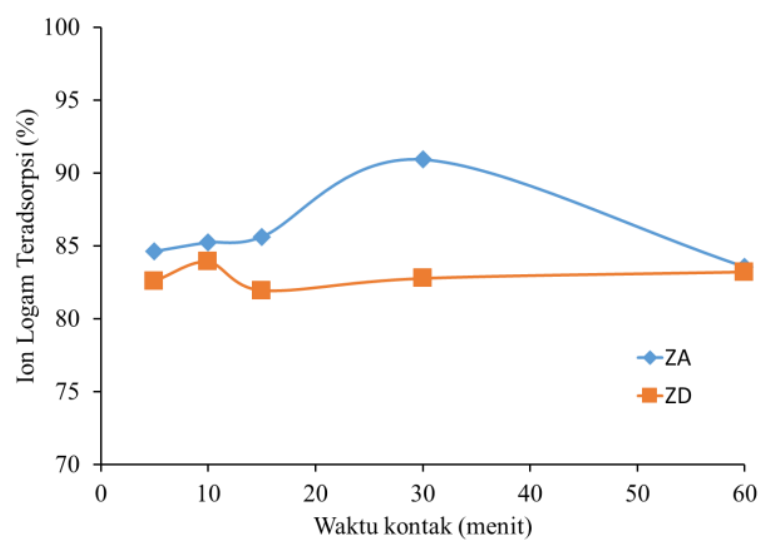

Gambar 2. Pengaruh waktu kontak pada adsorbsi logam

Gambar 2 menunjukkan bahwa antara Zeolit Aktif (ZA) dengan Zeolit-Ditizon (ZD) memiliki waktu kontak optimum yang berbeda. Adsorpsi logam $\mathrm{Cu}$ dengan ZA mencapai waktu kontak optimum pada 30 menit sedangkan ZD pada 10 menit dengan kapasitas adsorpsi $0,0568 \mathrm{~g} / \mathrm{g}$ dan $0,0524 \mathrm{~g} / \mathrm{g}$. Pada waktu tersebut terjadi adsorpsi paling besar dimana konsentrasi larutan yang teradsorpsi maksimal.

Pengaruh $\mathrm{pH}$ pada adsorpsi ion logam

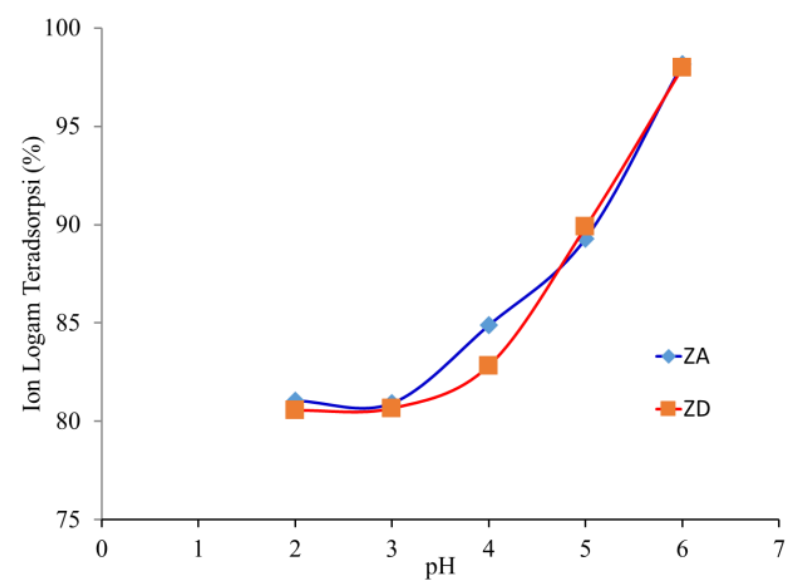

Gambar 3. Pengaruh pH pada adsorpsi $\mathrm{Cu}^{2+}$
Gambar 3 menunjukkan bahwa semakin besar $\mathrm{pH}$ larutan maka kapasitas adsorpsi adsorben semakin meningkat. Logam $\mathrm{Cu}$ dalam larutan dapat mengendap pada $\mathrm{pH}$ basa yaitu pada rentang $\mathrm{pH} 6 \mathrm{ke}$ atas. Logam $\mathrm{Cu}$ yang mengendap kemudian tersaring dengan kertas saring, sehingga saat pengukuran konsentrasi kadar $\mathrm{Cu}$ dalam larutan berkurang drastis. Berkurangnya konsentrasi logam $\mathrm{Cu}$ ini bukan disebabkan proses adsorpsi oleh adsorben melainkan karena terjadinya pengendapan karena pada pH 6 Ksp larutan lebih besar dari pada Ksp $\mathrm{Cu}$ yaitu $3 \times 10^{-19}$ sedangkan $\mathrm{Ksp} \mathrm{Cu}$ sebesar 4,8 $\times 10^{-20}$. Maka dari itu dalam adsorpsi ini disimpulkan bahwa $\mathrm{pH}$ optimum berada pada $\mathrm{pH} 5$ baik pada zeolit aktif maupun zeolit-ditizon.

Pengaruh konsentrasi pada adsorpsi ion logam

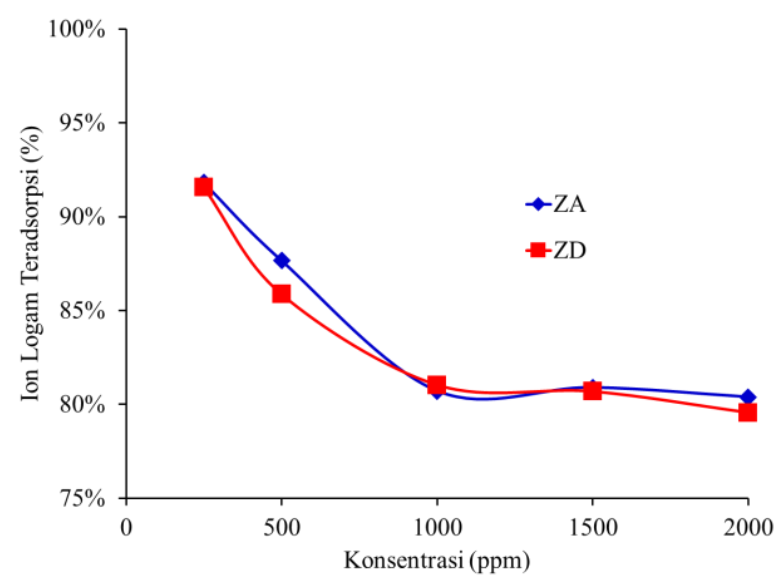

Gambar 4. Pengaruh konsentrasi pada adsorpsi $\mathrm{Cu}^{2+}$

Gambar 4 menunjukkan bahwa penyerapan optimum logam $\mathrm{Cu}$ dicapai pada konsentrasi rendah yaitu konsentrasi $250 \mathrm{ppm}$. Pada konsentrasi rendah, perbandingan jumlah mol dari ion logam menyebabkan permukaan situs aktif menjadi lebih luas dan adsorpsi dipengaruhi oleh konsentrasi awal larutan yang rendah [8].

\section{Hasil Analisa Luas permukaan dan Pori}

Untuk mengetahui karakteristik zeolit yang sudah termodifikasi oleh ditizon dilakukan karakteristik fisis yaitu analisa luas permukaan dan distribusi ukuran pori.

Tabel 1. Marfologi pori dan permukaan zeolite alam, zeolit aktifasi dan zeolite ditizon

\begin{tabular}{|c|c|c|c|c|}
\hline No & Sampel & $\begin{array}{l}\text { Luas } \\
\text { Permukaan } \\
\left(\mathrm{m}^{2} / \mathrm{g}\right)\end{array}$ & $\begin{array}{l}\text { Volume } \\
\text { Pori } \\
\text { (cc/g) }\end{array}$ & $\begin{array}{l}\text { Diameter } \\
\text { Pori }\left(A^{\circ}\right)\end{array}$ \\
\hline 1 & $\begin{array}{l}\text { Zeolit } \\
\text { Alam }\end{array}$ & 4,205 & 0,119 & 36,336 \\
\hline 2 & $\begin{array}{l}\text { Zeolit } \\
\text { Aktif }\end{array}$ & 5,459 & 0,123 & 36,51 \\
\hline 3 & $\begin{array}{c}\text { Zeolit } \\
\text { Ditizon }\end{array}$ & 0,925 & 0,024 & 157,432 \\
\hline
\end{tabular}

Tabel 1 menunjukkan luas permukaan zeolit aktif lebih besar dari zeolit alam. Namun luas permukaan zeolit ditizon lebih kecil dari zeolit aktif. Hal ini tidak sesuai dengan hipotesa awal yaitu seharusnya luas 
permukaan zeolit aktif dengan zeolit ditizon tidak berbeda jauh. Semakin kecilnya luas permukaan zeolit ditizon dikarenakan ditizon yang digunakan untuk modifikasi zeolit mengisi pori dari zeolit itu sendiri, sehingga volume porinya pun juga semakin kecil.

\section{Kesimpulan}

Kemampuan adsorpsi zeolit ditizon lebih rendah dibandingkan zeolit aktif, dengan waktu kontak optimum 10 menit untuk zeolit ditizon dan 30 menit untuk zeolit aktif, $\mathrm{pH}$ optimum yang digunakan yaitu $\mathrm{pH}$ 5 untuk kedua adsorben, serta konsentrasi optimum adsorpsi berada pada konsentrasi rendah yaitu $250 \mathrm{ppm}$ untuk kedua adsorben.

\section{Daftar Pustaka}

[1] Stanley E. Manahan, Environmental Chemistry, Seventh Edition, Taylor \& Francis, 1999.

[2] Carmen Paduraru, Lavinia Tofan, Investigations On The Possibility of Natural Hemp Fibers Use For $\mathrm{Zn}$ (Ii) Ions Removal From Wastewaters, Environmental Engineering and Management Journal, 7, 6, (2008) 687-693

[3] Fernando Ramôa Ribeiro, Zeolites: Science and Technology, Springer Netherlands, Netherlands, 1984 .

[4] Shaobin Wang, Yuelian Peng, Natural zeolites as effective adsorbents in water and wastewater treatment, Chemical Engineering Journal, 156, 1, (2010) 11-24 https://doi.org/10.1016/j.cej.2009.10.029

[5] Zygmunt Marczenko, Separation and spectrophotometric determination of elements, 2th edition ed., Ellis Horwood, 1986.

[6] Mohamed E. Mahmoud, Maher M. Osman, Osama F. Hafez, Abdelrahman H. Hegazi, Essam Elmelegy, Removal and preconcentration of lead (II) and other heavy metals from water by alumina adsorbents developed by surface-adsorbed-dithizone, Desalination, 251, 1, (2010) 123-130 https://doi.org/10.1016/j.desal.2009.08.008

[7] Achanai Buasri, Nattawut Chaiyut, Lalita Nammueng, Use of Natural Clinoptilolite for the Removal of Lead (II) from Wastewater in Batch Experiment, Chiang Mai Journal of Science, 35, 3, (2008) 447-456

[8] Li Jia Yu, Shyam S. Shukla, Kenneth L. Dorris, Alka Shukla, J. L. Margrave, Adsorption of chromium from aqueous solutions by maple sawdust, Journal of Hazardous Materials, 100, 1, (2003) 53-63 https://doi.org/10.1016/S0304-3894(03)00008-6 